\title{
UN CASO DE HIPODONCIA EN UN LOFIODÓNTIDO (PERISSODACTYLA, MAMMALIA) DEL EOCENO MEDIO DE LA CUENCA DEL DUERO (CASTILLA Y LEÓN, ESPAÑA). INTERPRETACIÓN A LUZ DE LA AGENESIA DENTARIA HUMANA
}

\author{
Miguel Angel CUESTA RUÍZ-COLMENARES ${ }^{1,2}$, \\ Emiliano JIMÉNEZ FUENTES ${ }^{2}$ y Pilar Julia \\ PÉREZ PÉREZ
}

${ }^{1}$ Avenida de Castilla, 49, 3 izda., 34005, Palencia. macuesta@agro.uva.es ${ }_{2}^{2}$ Departamento de Geología, Facultad de Ciencias, Universidad de Salamanca, 37008, Salamanca

${ }^{3}$ Departamento de Paleontología, Facultad de Ciencias Geológicas, Ciudad Universitaria, 28040 Madrid.

Cuesta Ruíz-Colmenares, M. A., Jiménez Fuentes, E. y Pérez Pérez, P. J. 2004. Un caso de hipodoncia en un lofiodóntido (Perissodactyla, Mammalia) del Eoceno medio de la cuenca del Duero (Castilla y León, España). Interpretación a luz de la agenesia dentaria humana. [A case of hypodontia in a lofiodontid (Perissodactyla, Mammalia) from the middle Eocene of the Duero basin (Castilla y León, Spain). Intrepretation in the light of human dental agenesis.] Revista Española de Paleontología, 19 (2), 145-150. ISSN 0213-6937.

\begin{abstract}
A case of hypodontia, a type of dental agenesis, is described in a lofiodontid (Perissodactyla, Mammalia) from the middle Eocene of the Duero bassin (Castilla y León, Spain). The fossil material consists in a mandible with all teeth possesing a pronounced wear except left $\mathrm{P} / 4$; this condition must be explained by the absence of the respective left $\mathrm{P} 4 /$. The hypodontia is a relatively common anomaly in the human dental development and is frequent in other mammal species. Inheritance seems to be the main factor involved in dental agenesis.
\end{abstract}

Key words: hypodontia, paleopathology, lofiodontids, perisodactils, Eocene, Duero bassin, Castilla y León, Spain.

\section{RESUMEN}

Se describe un caso de hipodoncia, un tipo de agenesia dentaria, en un lofiodóntido (Perissodactyla, Mammalia) procedente del Eoceno medio de la cuenca del Duero (Castilla y León, Spain). El material fósil consiste en una mandíbula con todos los dientes provistos de un acusado desgaste a excepción del P/4 izquierdo; esta condición debe ser explicada por la ausencia del correspondiente P4/ izquierdo. La hipodoncia es una anomalía relativamente frecuente en el desarrollo dental humano y es frecuente en otras especies de mamíferos. La herencia parece ser el principal factor implicado en la agenesia dentaria.

Palabras clave: hipodoncia, paleopatología, lofiodóntidos, perisodáctilos, Eoceno, cuenca del Duero, Castilla y León, España.

\section{INTRODUCCIÓN}

Recientemente (Cuesta et al., 2003) se ha documentado un caso de paleopatología dentaria en un resto fósil de lofiodóntido (Perissodactyla, Mammalia) extraído en el ya- cimiento eocénico de Corrales del Vino (Zamora, Castilla y León, España). El objeto de este trabajo es ampliar la información concerniente al citado caso.

El material motivo de este trabajo es una mandíbula de perisodáctilo ( $\mathrm{N}^{\circ}$ STUS 14.053) que fue extraída en las 
excavaciones de 1993 de la Junta de Castilla y León y se encuentra depositada en la Facultad de Ciencias de la Universidad de Salamanca a cuya colección corresponde la numeración de la pieza.

El yacimiento de vertebrados de Corrales del Vino (Zamora) se encuentra situado en las cercanías de la localidad del mismo nombre, provincia de Zamora (Fig. 1). Pertenece a la denominada Área de Casaseca, conjunto de unas 50 localidades fosilíferas de vertebrados paleógenos situada al sur de la ciudad de Zamora (Gil, 1992); a su vez dicha zona se localiza en el afloramiento paleógeno suroccidental de la cuenca del Duero. La lista faunística del yacimiento (Cuesta, 1999; Jiménez, 2003) incluye mamíferos (perisodáctilos), varios reptiles (quelonios y cocodrilos) y peces. Los perisodáctilos están representados por lofiodóntidos, con dos formas (Paralophiodon aff. isselense (Fischer, 1829) y Lophiodontidae?) junto con escasos ecuoideos de determinación difícil (Cuesta, 1994a y b). La edad, determinada esencialmente a partir de la asociación de perisodáctilos y por correlación con el cercano yacimiento de Casaseca, es MP 13-14, Luteciense superior-Bartoniense inferior (parte media del Eoceno medio).
PALEONTOLOGÍA SISTEMÁTICA

ORDEN PERISSODACTYLA Owen, 1848

SUBORDEN TAPIROMORPHA Haeckel, 1873 (sensu

Hooker, 1984)

INFRAORDEN ANCYLOPODA Cope, 1889 (sensu

Hooker, 1989)

Familia Lophiodontidae Gill, 1872

Lophiodontidae indet.

Fig. 2

Material: mandíbula ( ${ }^{\circ}$ STUS 14.053, Facultad de Ciencias, Universidad de Salamanca)

Localidad: Corrales del Vino (cuenca del Duero, provincia de Zamora, Castilla y León, España).

Edad: Luteciense superior-Bartoniense inferior, MP 13-14 (parte media del Eoceno medio).

Descripción y discusión: La mandíbula tiene la rama horizontal derecha completa y la izquierda rota detrás de $\mathrm{M} / 1$ (Fig. 2). Conserva los seis incisivos y los dos caninos, la serie yugal derecha completa $(\mathrm{P} / 2, \mathrm{P} / 3, \mathrm{P} / 4, \mathrm{M} / 1$,

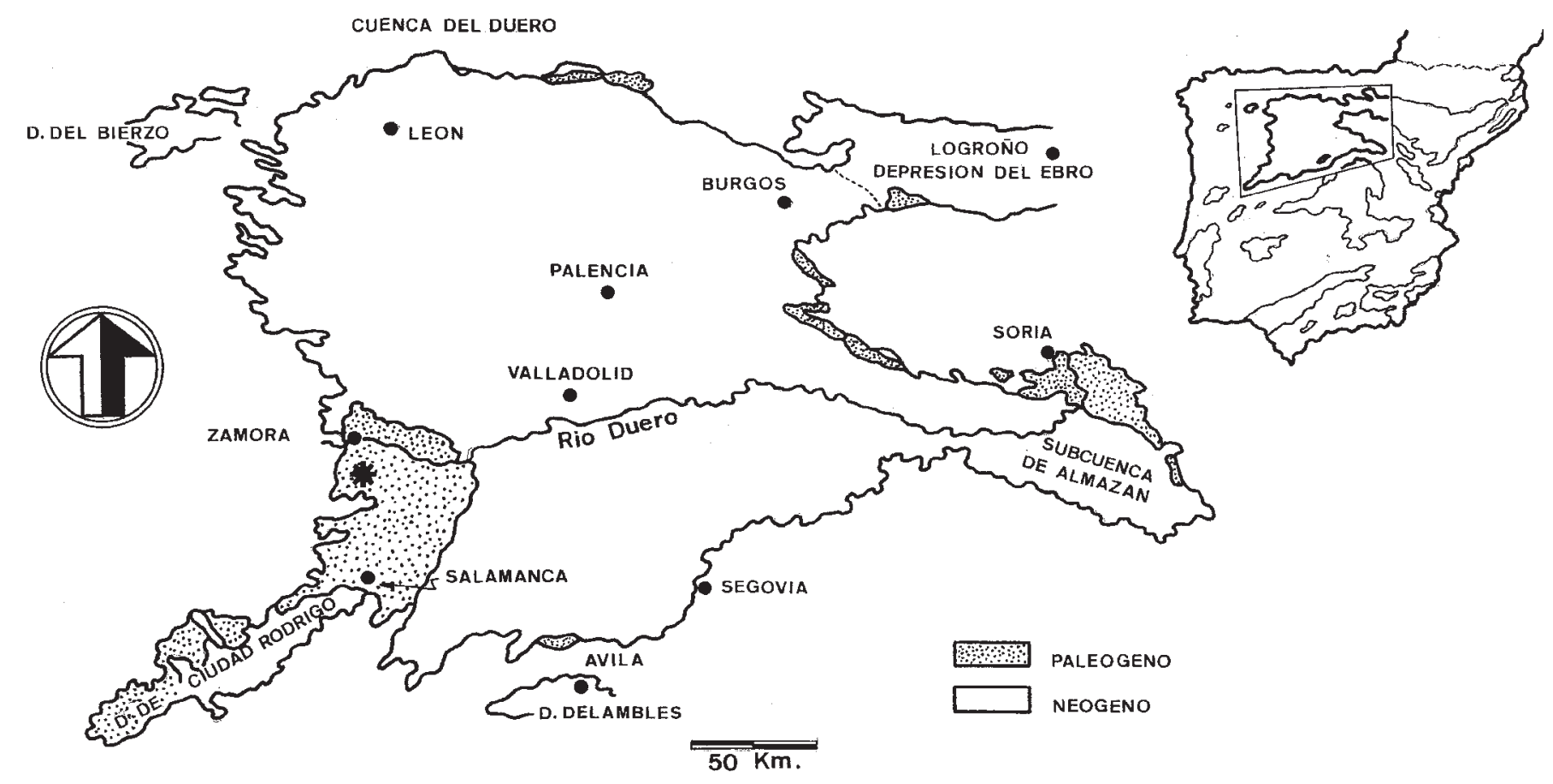

Figura 1. Situación geográfica (asterisco) del yacimiento de Corrales del Vino (Eoceno medio, provincia de Zamora, Castilla y León, España).

Geographical situation (asterisk) of Corrales del Vino bed (middle Eocene, Zamora province, Castilla and León, Spain). 


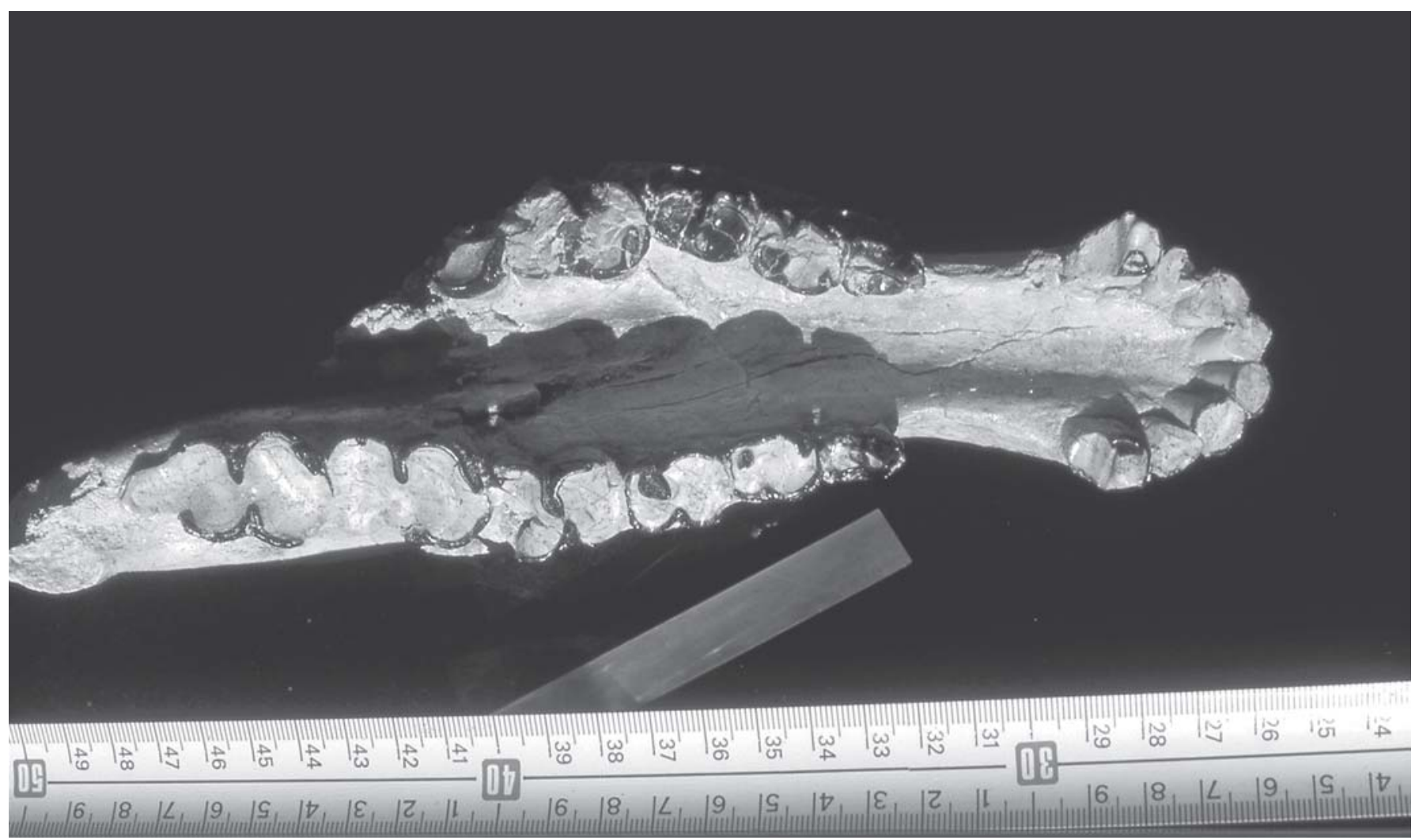

Figura 2. Mandíbula de Lophiodontidae indet. (STUS 14.053) en vista oclusal; se aprecia la ausencia diferencial de desgaste en el P/4 izquierdo; Corrales del Vino (Eoceno medio, provincia de Zamora, Castilla y León, España).

Mandible of Lophiodontidae indet (STUS 14.053) in occlusal view; notice the differential lack of wear in the left P/4; Corrales del Vino bed (middle Eocene, Zamora province, Castilla y León, Spain).

$\mathrm{M} / 2$ y $\mathrm{M} / 3$ ) y en el lado izquierdo $\mathrm{P} / 2, \mathrm{P} / 3, \mathrm{P} / 4, \mathrm{M} / 1$ algo incompleto en la cara lingual y el ángulo antero-interno de $\mathrm{M} / 2$. La longitud de las piezas de la serie yugal derecha es, desde $\mathrm{P} / 2$ a $\mathrm{M} / 3$ respectivamente $16,17,20,26$, 32 y $42 \mathrm{~mm}$, y sus anchuras 10, 13, 16, 19, 23 y $24 \mathrm{~mm}$. El punto más caudal de la sínfisis mandibular está a la altura del talónido de P/4. El diastema postcanino es largo. Los caninos son pequeños, sólo ligeramente mayores que los incisivos lo que denota que el individuo debió ser hembra ya que los caninos alcanzan un tamaño absoluto y relativo mucho mayor en otros individuos de lofiodóntidos presumiblemente machos.

Todas las piezas, a excepción del P/4 izquierdo, presentan un elevado grado de desgaste habiendo sido enrasada la corona casi hasta su base; se trata, por tanto, de un individuo adulto de edad avanzada. Dicho P/4 izquierdo está apenas usado conservando prácticamente íntegros los dos lóbulos, trigónido y talónido. Los cónidos del trigónido (protocónido y metacónido) son altos y poco separados; el paralófido, que está ligeramente desgastado en su cresta superior, es bajo y está dirigido lingualmente hasta unirse al cíngulo anterior. En el talónido, el hipocónido es más bajo y menos potente que los dos cónidos anteriores, y de él salen unos bajos metalófido e hipolófido.
La morfología dentaria de la mandíbula estudiada corresponde a un perisodáctilo tapiromorfo, en concreto perteneciente a la familia de los lofiodóntidos, grupo que alcanzó una importancia notable en el Eoceno inferior y medio de Europa occidental. El grado de desgaste de las piezas dentarias, a excepción del $\mathrm{P} / 4$, impide su asignación genérica dentro de la mencionada familia de perisodáctilos. En Corrales y en el yacimiento de Casaseca, de edad similar y muy cercano a aquella localidad, se han descrito varios lofiodóntidos (Cuesta, 1994a). De ellos, Lophiodontidae indet. de Casaseca (afín al género Lophiaspis Depéret, 1910) es de talla claramente menor y Lophiodontidae? de Corrales de morfología muy diferente. Por su parte, Lophiodon cf. tapirotherium (Desmarest, 1822) de Casaseca presenta varias diferencias que impiden la asignación de la pieza con esta forma que tiene: talla bastante mayor, canino e incisivos mucho más grandes, I/3 muy poderosos en relación a los otros incisivos, extremo caudal de la sínfisis en posición más anterior (entre $\mathrm{P} / 3$ y $\mathrm{P} / 4$ ), $\mathrm{M} / 1$ proporcionalmente menos desarrollado en relación al $\mathrm{P} / 4$ y M/3 con hipoconúlido mucho más ancho. Las mayores similitudes de la mandíbula estudiada se observan con Paralophiodon aff. isselense (Fischer, 1829) presente tanto en Corrales como en 

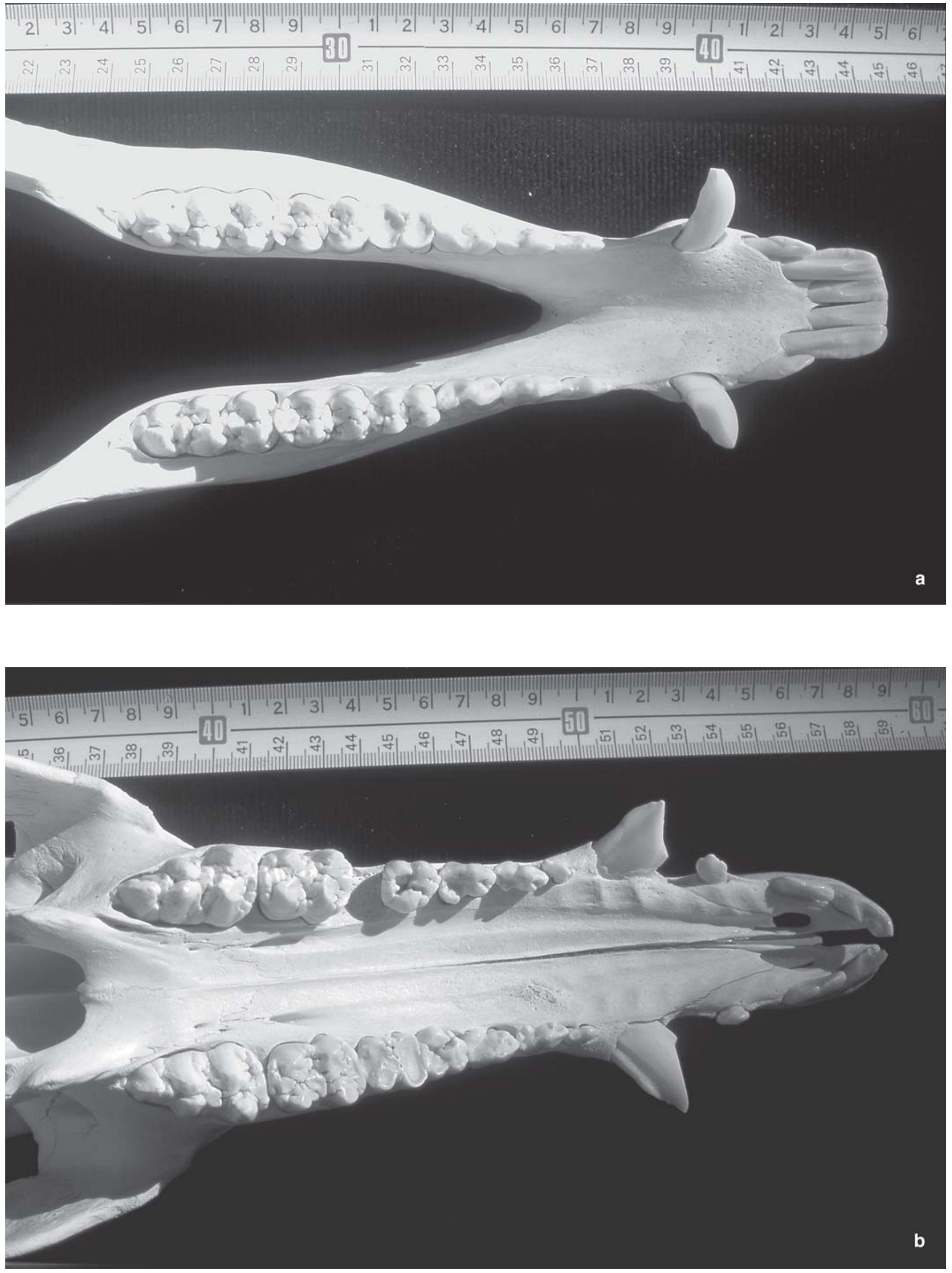
Casaseca, si bien también se aprecian varias diferencias respecto a esta última forma: talla algo menor, incisivos y canino menores, diastema más largo y extremo caudal de la sínfisis más retrasado. Por otra parte no puede apreciarse, debido al desgaste, la estructura "rinocerotoide" típica del género Paralophiodon Dedieu, 1977.

En conclusión, no podemos asignar de momento la pieza a ninguna de las formas de lofiodóntidos descritas en Corrales y Casaseca, los yacimientos de la zona donde mejor están documentados los lofiodóntidos.

\section{DESCRIPCIÓN DE LA PALEOPATOLOGÍA}

Como se ha descrito más arriba, el P/4 izquierdo de la mandíbula estudiada está apenas usado conservando prácticamente íntegros los dos lóbulos, trigónido y talónido, con sus cónidos sin desgastar. Esta ausencia diferencial de desgaste en el P/4 izquierdo se explica forzosamente por la falta del correspondiente diente superior que ocluye con él, es decir, el P4/ izquierdo. Esta situación, conocida como anodoncia en sentido amplio o agenesia dentaria, es una anomalía dentomaxilofacial que consiste en la ausencia de formación de un germen dental que se manifiesta en la falta del correspondiente diente en la dentición, bien de leche bien definitiva.

Existen varios tipos de agenesia dental definidos para la especie humana (Cautley, 1928) tanto para poblaciones actuales como para el hombre fósil: hipodoncia o anodoncia parcial (ausencia de hasta seis dientes), oligodoncia (ausencia de más de seis dientes) y anodoncia total o anodoncia vera (ausencia total de gérmenes dentarios).

La agenesia de dientes permanentes es una anomalía relativamente común en el desarrollo dental del hombre. En poblaciones actuales su incidencia varía (ver Berrocal, 2003), siendo por ejemplo del 10-25\% en Norteamérica y del $5-10 \%$ en las poblaciones asiática y europea. La agenesia más común es en los terceros molares (6-7\%); ello es debido a la tendencia evolutiva a la desaparición de estas piezas en particular, dentro de la tendencia a la reducción de la dentición del hombre moderno (ver por ejemplo Mendoza et al., 1994); la radiografía revela en cada caso si verdaderamente hay ausencia de germen dental. En segundo lugar afecta a los segundos premolares inferiores (1-6\%) y por último a los incisivos laterales superiores $(1-4 \%)$.

La perdida del tercer molar en Homo sapiens se ha interpretado dentro del marco de los procesos de hetero- cronía como un fenómeno de post-desplazamiento, consecuencia de la tendencia filogenética al retraso en el comienzo de la formación de esta pieza dentaria. Bermudez de Castro (1989) ha tratado el tema con ocasión de un estudio sobre evidencia de agenesia dentaria en canarios prehispánicos. Ortner y Putschar (1985) aportan un caso de agenesia de incisivos laterales inferiores en un cráneo y mandíbula de un individuo femenino adulto procedente de un yacimiento arqueológico de Dakota. Estos autores citan varios ejemplos de dientes supernumerarios, mucho más frecuentes en la literatura paleopatológica que los casos de hipodoncia. En el Museo de Historia Natural de París se observan dos casos de poligénesis en primates, en el cráneo y mandíbula del gorila 1866 con un cuarto molar superior derecho en el cráneo, reducido, con sólo dos cúspides, y cuartos molares inferiores en la mandíbula, también reducidos, y en la mandíbula de otro gorila con dos incisivos laterales en el lado izquierdo (Pérez y Rosas, 1992).

Casos similares al estudiado aquí se observan en ejemplares de otras especies actuales de mamíferos, en los que la falta de una pieza dentaria provoca la ausencia de desgaste en la pieza opuesta que ocluye con ella; tal es el caso del ejemplar de jabalí (Sus scrofa, $\mathrm{N}^{\circ}$ STUS 14.054) que aparece en la figura 3 en el cual la ausencia de M1/ derecho en el maxilar superior ha causado la falta de desgaste del M/1 derecho que ocluiría con él en una situación normal, mientras que el M/1 izquierdo aparece con elevado grado de desgaste ya que el correspondiente M1/ izquierdo sí está presente. Para una recopilación de alteraciones paleopatológicas en Paleozoología y Arqueozoología, incluidas las dentarias ver Pérez (2003).

Los factores más comunes asociados con la agenesia dental en humanos son evolutivos en general y hereditarios en particular. El fenómeno se ha observado durante siglos en familias a través de varias generaciones (hipodoncia familiar) por lo que el patrón de herencia ha sido establecido para la mayoría de estas alteraciones (ver por ejemplo Erwin y Cockern, 1949). La forma más común de herencia de la agenesia dental es de tipo autosómico dominante si bien se han observado también los patrones autosómico recesivo y ligado al cromosoma X (Briceño et al., 2003). En concreto, la hipodoncia congénita parece ser el resultado de una o más mutaciones puntuales en un sistema poligénico ligado cerrado, más a menudo transmitida según un patrón autosómico dominante. Se han identificado varios genes del desarrollo, con sus correspondientes locus, cuyas mutaciones causan hipodoncia.

Figura 3. a, Mandíbula de jabalí (STUS 14.054) en vista oclusal con diferencia de desgaste entre el M/1 derecho y el M/1 izquierdo. b, Maxilar del mismo individuo en vista oclusal, con hipodoncia en el M1/ derecho.

$\boldsymbol{a}$, Mandible of wild boar in occlusal view with difference of wear between the right M/1 and the left M/1. b, Maxilar of the same individual in occlusal view with hypodontia in the right MI/. 
Entre ellos destacan el MSX1 para la forma autosómica dominante, el gen PAX 9 asociado a oligodoncia y el gen EDA (gen de la displasia ectodérmica anhidrótica) en la forma ligada a X (Vastardis et al., 1996; Van den Boogaard et al., 2000). Dado que intervienen varios genes, la hipodoncia es una condición genética heterogénea en donde más de un gen defectuoso contribuye a una gran variabilidad de casos; además, la expresividad variable contribuye a aumentar el número de posibilidades existiendo casos de expresividad más leve con ausencia unilateral no bilateral de alguna pieza dentaria (Correa y García-Robes, 1996). Existen otros posibles factores causales de agenesia dental: traumatismos, infección durante el desarrollo dental, disfunción glandular, raquitismo, ciertas enfermedades durante el embarazo y disturbios intrauterinos severos (Berrocal, 2003).

\section{CONCLUSIONES}

En la mandíbula STUS 14.053 proveniente del yacimiento del Eoceno medio de Corrales del Vino (cuenca del Duero, provincia de Zamora) se observa una ausencia diferencial de desgaste en el P/4 izquierdo. Tal situación se supone provocada por la falta del correspondiente $\mathrm{P} 4 /$ izquierdo que ocluiría con él en el animal vivo. Si bien no pueden descartarse otros factores, la causa más probable de la ausencia del P4/ es la agenesia dental (hipodoncia) que en poblaciones humanas actuales se ha comprobado tiene por lo general una base genética.

Agradecimientos: a Eva Torre por su revisión de las partes en inglés; a Angel Cuesta, autor del mapa.

\section{BIBLIOGRAFÍA}

Bermúdez de Castro, J.M. 1989. Third Molar Agenesis in Human Prehistoric Population of the Canarian Island. American Journal of Physical Anthropology, 79, 207-215.

Berrocal, M.C. 2003. La Hipodoncia: un análisis genético. http://www.encolombia.com/odontologia/investigaciones/ memorias-IVencuentro-hipodoncia.htm

Briceño, I., Berrocal, M.C., González, O.A., Gutiérrez, S.J., Ordóñez, A. y Torres, D. 2003. Análisis clínico y molecular de la hipodoncia. http://www.encolombia.com/odontologia/investigaciones/memorias- $\mathrm{V}$ encuentro-analisis.htm

Cautley, R.L. 1928. Abnormalities of the human dentition. British Dental Journal, 49, 669.

Correa, B. y García-Robes, M. 1996. Agenesia dentaria: Estudio familiar. http://www.infomed.sld.cu/revistas/ord/ vol11_1_96/ord05196.htm
Cuesta, M.A. 1994a. Los Lophiodontidae (Perissodactyla, Mammalia) del Eoceno de la Cuenca del Duero (Castilla y León, España). Stvdia Geologica Salmanticensia, 29, 23-65.

Cuesta, M.A. 1994b. Los Pachynolophinae (Equoidea, Perissodactyla, Mammalia) del Eoceno de la Cuenca del Duero (Castilla y León, España). Stvdia Geologica Salmanticensia, 30, 21-63.

Cuesta, M.A. 1999. Las faunas de mamíferos del Eoceno de la Cuenca del Duero (Castilla y León, España). Síntesis bioestratigráfica y biogeográfica. Revista Española de Paleontología, 14, 203-216.

Cuesta, M.A., Jiménez, E. y Pérez, P.J. 2003. Un caso de hipodoncia en un lofiodóntido (Perissodactyla, Mammalia) de Eoceno medio de la cuenca del Duero (Castilla y León, España). Libro de resúmenes, XIX Jornadas de la Sociedad Española de Paleontología, Morella 2003, 59-60.

Erwin, W.G. and Cockern, R-W. 1949. A pedigree of partial anodontia. Journal of Heredity, 40, 215-218.

Gil, S. 1992. Yacimientos de Vertebrados paleógenos de Castilla y León. In: Vertebrados fósiles de Castilla y León (Coord. E. Jiménez). Museo de Salamanca, Salamanca, 27-37.

Jiménez, E. 2003. Predación crocodiliana a quelonios. Un Neochelys (Pelomedusidae), del Eoceno de Zamora, lisiado por un Asiatosuchus. Stvdia Geologica Salmanticensia, 39, 11-23.

Mendoza, A., Domínguez, A. y Solano, E. 1994. Agenesia dentaria: estudio de su prevalencia sobre una muestra de 2.000 pacientes en Andalucía. Revista Iberoamericana de Ortodoncia, 13, 113-121.

Ortner, D.J. and Putschar, W.C., 1985. Pathological Conditios in Human Skeletal Remains. Smithsonian Institution Press, Washington, 493 pp.

Pérez, P. J. 2003. Paleopatología animal. In: Los vertebrados fósiles en la historia de la vida. Excavación, estudio y patrimonio (Eds. E. Jiménez y J. Civis). Ediciones Universidad de Salamanca, Salamanca, 321-361.

Pérez, P.J. y Rosas, A. 1992. Identificación de procesos patológicos en restos esqueléticos de Primates. Munibe (Antropologia- Arkeologia), Supl. 9, 9-105.

Van den Boogaard, M.J., Dorland, M., Beemer, F.A. and Ploos van Amstel, H.K. 2000. MSX1 mutation is associated with orofacial clefting and tooth agenesis in humans. Nature Genetics, 24, 342-343.

Vastardis, H., Karimbux, N., Guthua, S.W., Seidman, J.G. and Seidman, C.E. 1996. A human MSX1 hemeodomain missense mutation causes selective tooth agenesis. Nature Genetics, 13, 417-421.

Manuscrito recibido: 1 de diciembre, 2003 Manuscrito aceptado: 14 de septiembre, 2004 